\title{
DESIGN AND FABRICATION OF AUTONOMOUS ROBOT FOR
}

\section{PRECISION AGRICULTURE}

\author{
S. RAMESH KUMAR ${ }^{1}$, H. SRIRAM KALYAN ${ }^{2}$, K. DHANANJAYA KUMAR ${ }^{3} \&$ S. DILIP $^{4}$ \\ ${ }^{I}$ Assistant Professor, Department of Mechanical Engineering, Koneru Lakshmaiah Education Foundation, \\ Guntur, Andra Pradesh, India \\ ${ }^{2,3,4}$ Under Gratuate Students, Department of Mechanical Engineering, Koneru Lakshmaiah Education Foundation,
} Guntur, Andra Pradesh, India

\begin{abstract}
Autonomous robots are used for the ease of operation and automating the agricultural sector, which in turn helps in high yield and reduction in labor cost. Automated robots are being used in many of the fields such as Agriculture, field scouting, surveillance, industries to reduce the time delay in operation at different levels of the work environment. In this paper, the proposed system is designed and fabricated for the agricultural applications like cultivating without the limited use of manpower. The point of the paper is to lessen the labor and time, assist an expansion in the profitability rate. The basic automation robot is involved in agricultural operations like a removal of weed, harvesting and so on. The designed system performs the operations such as seed sowing, plowing, applying fertilizers during the vehicle in operation. These are performed by the autonomous robot using the microcontroller. The proposed system is equipped with an ultrasonic sensor, which helps in detecting the obstacles and its avoidance. The system architecture is designed and simulated using Proteus. Small and large scale farming can be achieved using either a single robot or by a number of small robots depending upon the area.
\end{abstract}

KEYWORDS: Seeding, Microcontroller, Ultrasonic Sensor \& Proteus

Received: Mar 24, 2018; Accepted: Apr 14, 2018; Published: May 05, 2018; Paper Id.: IJMPERDJUN201842

\section{INTRODUCTION}

India is an agricultural country and most of the people depend on agriculture to earn money predominately and fulfil their needs. The financial condition of India depends on agriculture and farmer economy. Now a day's farming labor availability is decreasing regularly, method of farming is undergoing various upgrades over the time. Agricultural practices have improved and are speeding up with the help of machines. The machine helps in improving the yield and reduces time for work required in the farmland. Most machines are huge and heavy which can be used only in a large agricultural field. These machines may damage the land by soil compaction. Also, these machines require lots of fuel and require maintenance during operation. With the increase in population the farmland has reduced. Many farmers have a small plot of land for agriculture. These farmers cannot support the huge machineries in their agricultural land due to the huge cost of the machinery. Agriculture sector can be modified and transformed with the introduction of small autonomous robots. The robots which do multiple operations are much better than the huge machines which only perform a single operation.

The farming process uses a robot with microcontroller for autonomous agriculture. The primary phase includes moving the assembled robot over the farmland from one end to another and also identification of the 
obstacles in the way and reorienting to the specified path to cover the entire field. The robot was designed for showing different types of seeds. The second phase includes watering and spraying of pesticides during operation. Manual spraying of pesticides causes many health hazards. So the proposed system contributes a technical solution by designing an operational autonomous spraying agricultural robot. The farmer with minimum knowledge can control the robot, far away. The spraying unit is capable of spraying evenly and efficiently in the field, hence reduces the risk to the farmer's health during various farming operations.

The fundamental target of sowing activity is to put the seed and compost in lines at wanted profundity and seed to seed dividing, cover the seeds with soil and give legitimate compaction over the seed. The prescribed line to push dispersing, seed rate, seed to seed dividing and profundity of seed situation shift from harvest to trim and for various agroclimatic conditions to accomplish ideal yields.

\section{Sowing Methods}

In the present situation various sowing techniques are applied based on the type of crop and the land, weather conditions. Each method has its own pros and cons.

\section{List of Sowing Methods}

- Broadcasting

- Broad or Line sowing

- Dibbling

- Transplanting

- Planting

- Putting seeds behind the plough.

\section{Customary Sowing Techniques have Following Limitations}

- In manual seeding, it isn't conceivable to accomplish consistency in dissemination of seeds.

- An agriculturist may sow at a wanted seed rate, however, between push and intra-Column appropriation of seeds is probably going to be uneven bringing about clustering and holes in the field.

- Poor control over the profundity of seed arrangement is additionally a restriction. Work prerequisite is high since two people are required for dropping seed and compost.

- The impact of errors in seed position will be more in the case of crops

Table1. Seed Size of different plants

\begin{tabular}{|l|c|}
\hline Type of the Seed & $\begin{array}{c}\text { Diameter of the } \\
\text { Seed in }(\mathbf{m m})\end{array}$ \\
\hline Beet & 7.0 \\
\hline Cabbage & 40 \\
\hline Carrot & 3.8 \\
\hline Cauliflower & 42 \\
\hline Corn & 16 \\
\hline
\end{tabular}




\begin{tabular}{|l|c|}
\hline \multicolumn{2}{|c|}{ Table 1: Contd., } \\
\hline Onion & 8.0 \\
\hline Pea & 9.0 \\
\hline Radish & 3.5 \\
\hline
\end{tabular}

Table2. Norms for Planting Seeds

\begin{tabular}{|l|c|c|}
\hline $\begin{array}{c}\text { Type of the } \\
\text { Plant }\end{array}$ & $\begin{array}{c}\text { Distance between } \\
\text { Plants }(\mathbf{c m})\end{array}$ & $\begin{array}{c}\text { Planting Depth } \\
(\mathbf{c m})\end{array}$ \\
\hline Beet & $3-5$ & 1.5 \\
\hline Cabbage & 45 & $0.5-1.5$ \\
\hline Carrot & $3-5$ & 1.5 \\
\hline Cauliflower & $45-60$ & $0.5-1.5$ \\
\hline Corn & $15-25$ & 2.5 \\
\hline Onion & $5-8$ & $1.5-3$ \\
\hline Potato & $25-30$ & 10 \\
\hline Radish & 2.5 & 1.2 \\
\hline
\end{tabular}

\section{Hardware Specification}

\begin{tabular}{|c|l|l|}
\hline S. No & \multicolumn{1}{|c|}{ Component } & \multicolumn{1}{c|}{ Specification } \\
\hline 1 & Microcontroller & Atmega 8 \\
\hline 2 & DC Motor & High torque dc motor(100rpm \\
\hline 3 & Motor Driver Ic & L298N \\
\hline 4 & Drum Seed Motor & 10 rpm Dc motor \\
\hline 5 & Motor Pump Sprinkle & $12 \mathrm{v}$ Dc motor pump \\
\hline 6 & Battery & $12 \mathrm{~V}, 2$ Amp Lead acid battery \\
\hline 7 & Lcd Display & $16 \times 2$ \\
\hline 8 & Bluetooth & He-05 \\
\hline 9 & Ultrasonic sensor & HC-SR04 \\
\hline 10 & Servo motor & MG 995 \\
\hline 11 & DC Gear Motor & 12 volt, 7amp, L type \\
\hline
\end{tabular}

\section{FLOW CHART}

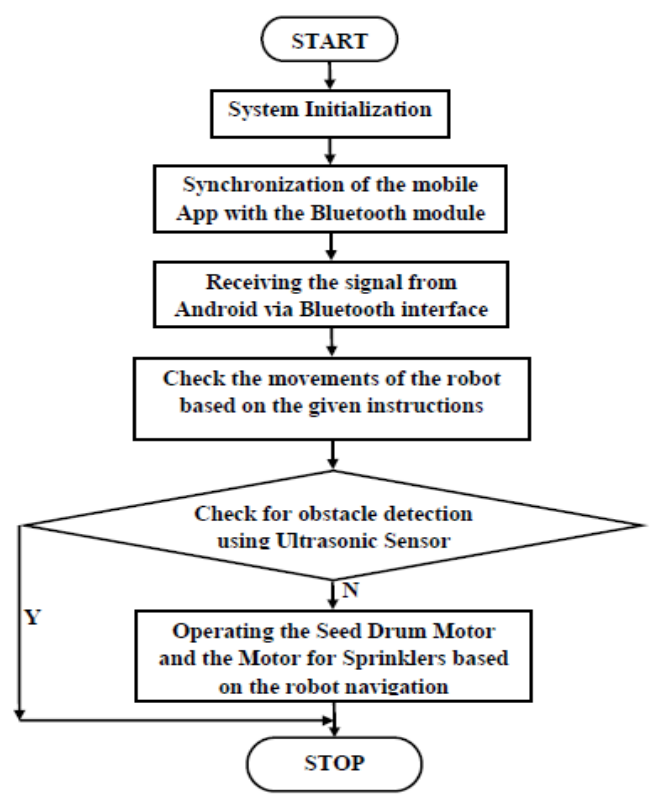




\section{Block Diagram}

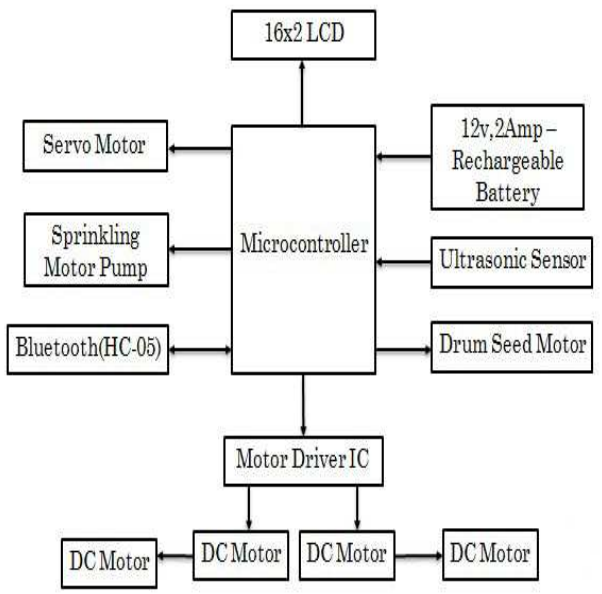

\section{SIMULATION}

The logic for the purpose of navigation and simulation of the robot is done with the help of the proteus software tool. The Proteus Design Suite is a Window based application for schematic capture, simulation, and PCB layout design and for organizing the microcontroller simulation. The Network diagram is built into the proteus software for the applications, tosense the obstacle in the moving path, turn on/off of the sprinklers for spraying and also to rotate the Seed drum.

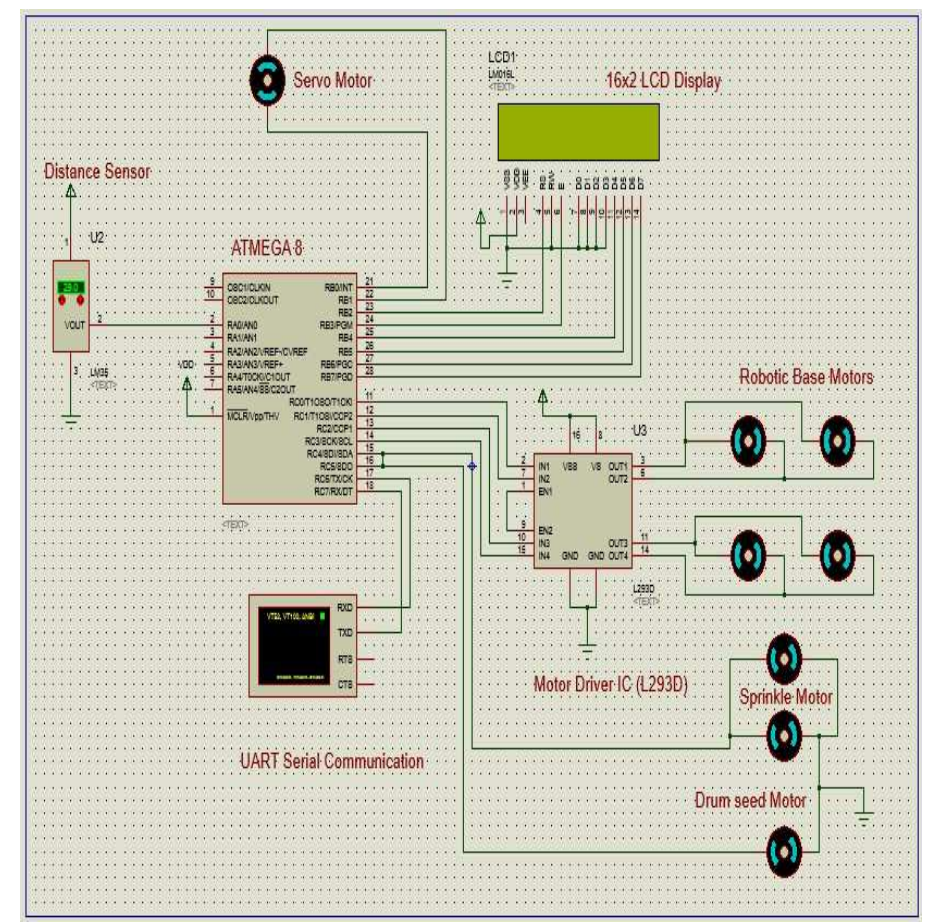

Figure 1: Logic Layout Circuit Using Proteus

\section{DESIGN PARAMETERS}

Size of wheel $=130 \mathrm{~mm}$ diameter

Total Wight of machine $=12 \mathrm{~kg}$ 
Number of drive motors $=4$

Number of Servo Motor=1

Number of geared Motors $=1$

By considering the above specifications. The motors for the navigation of the robot are selected such that it can generate an angular velocity of $31.496 \mathrm{rad} / \mathrm{sec}$, with a torque of $0.678 \mathrm{Nm}$. So the motors have been selected having an MaX Torque of $600 \mathrm{rpm}$.

\section{MODEL OF THE PROPOSED ROBOT DESIGN USING SOLID WORKS}

During designing the robot we have considered the physical conditions as well as the requirements suitable for planting and watering the seeds as per the need.

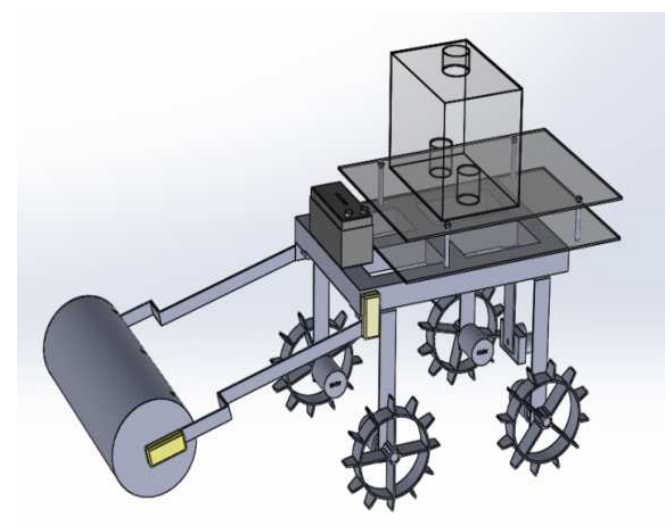

Figure 2: Solid Model of the Proposed Robot

The robot is designed and fabricated in such a way that the same device can be used for planting various seeds by simply changing the de attachable drum, which varies in its size and the span of slots.

The row span is equal to the circumference of the drum and the column span is equal to the distance between the slots (holes) provided on the drum.

The seed drum is being operated with the help of a motor provided at one end and also other motor is provided at the end of the drum supporting arms to raise and lower the position of the drum during the sowing process.

\section{ULTRASONIC SENSOR INTERFACE WITH ATMEGA 8}

The ultrasonic sensor is used to detect the obstacle when the robot is in operation. The ultrasonic sensor interface with at mega 8. Hc-SR04 is the sensor used for obstacle detection.

\section{SELECTION OF PUMP}

The fertilizer is mixed in the water. From the conventional observation approximately 350 liter of required to fertilize one acre of land and approximately 3 hours needed to seeding process. The discharge of the pump $=350 / 3=$ $116.667 \mathrm{liter} / \mathrm{hr}=1.944 \mathrm{liter} / \mathrm{min}$, the pump should deliver the discharge above $1.944 \mathrm{lpm}$. The selection of a pump is done based on the discharge capacity, i.e 2 liters per minute.

Discharge $=2$ to $5 \mathrm{lpm}$ Pressure $=5$ to $8 \mathrm{~kg} / \mathrm{cm} 2$ Operating RPM $=200$ to 250 


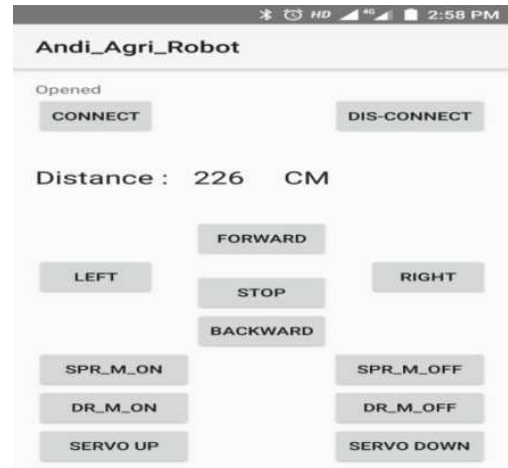

Figure 3: Developed Mobil App with Bluetooth Interface to Control the Robot Navigation
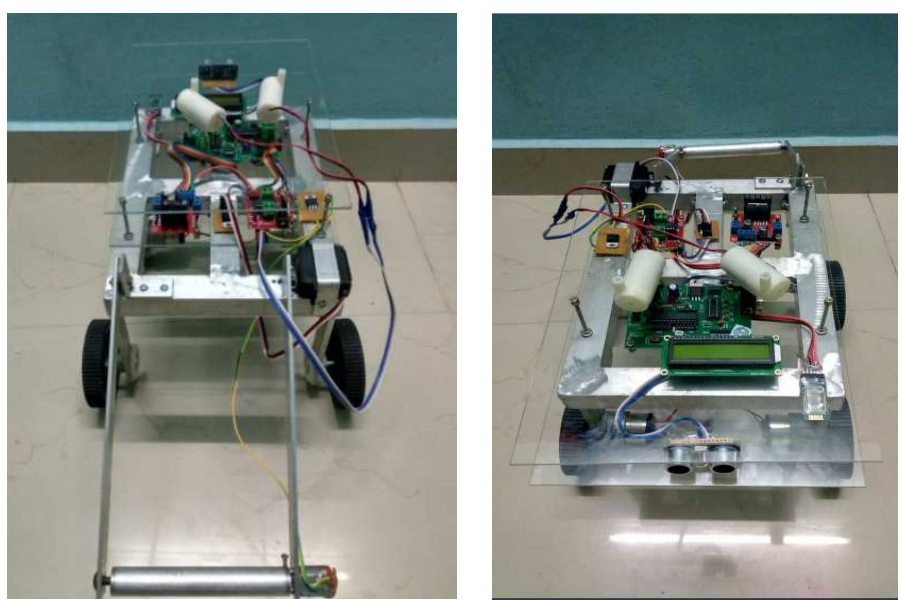

Figure 4: Fabricated Model of Seed Sowing Robot

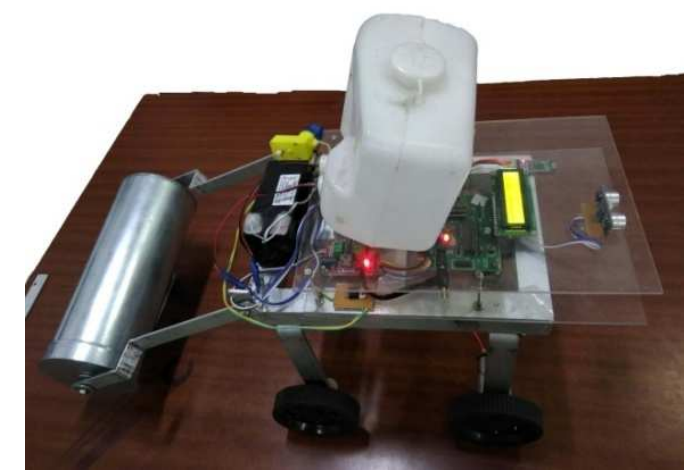

Figure 5:

\section{FEATURES OF SEED SOWING ROBOT}

- With the help of inventive seed sowing hardware, the seed can be sustained into the dirt consistently with no confinement.

- The vast majority of seed sowing types of gear machines said above require just a single individual to work. Subsequently, it decreases work cost.

- The general cost of seed sowing procedures will be lessened by utilizing this seed sowing machine. 
- These machines can likewise be utilized for sowing distinctive sorts of seeds. It is useful for little and medium scale agriculturists.

\section{Advantages}

- Improved efficiency in planting.

- Increased yields and reliability in the crop. Increased cropping frequency.

- Increased speed of seed planting.

- $\quad$ Seed planting accuracy.

- Durable and cheap as low-cost materials are used.

- Low maintenance cost.

- Seed can be placed at any specified depth, such that it improves the plant germination.

- With a limited number of agricultural labor the seed sowing process can be completed in short time.

- Uniformity will be maintained while placing the seeds in a row with specified distance.

- A spacing between seeds is provided such that proper lighting will be captured by the plant.

\section{Disadvantages}

- If any disturbance in the electrical set up it difficult for the farmer to handle (Need some expertise in electrical circuit connection)

- The battery needs to be charged after a certain time.

- An initial cost of the robot is high.

- Whenever the robot comes across an obstacle the farmer needs to adjust the robot with the help of the mobile app.

\section{RESULTS}

The working model of the robot discharges the seed sowing of various plants as specified in the table in the real field environment.

The Fabricating cost of the proposed model will be around Rs.6500/-

Table3: Seed Sowing Distance Generated in Row

\begin{tabular}{|l|c|}
\hline $\begin{array}{c}\text { Type of the Plant } \\
\text { (Vegetable) }\end{array}$ & $\begin{array}{c}\text { Planting Distance } \\
\text { between Plants (cm) }\end{array}$ \\
\hline Beet & 6 \\
\hline Cabbage & 46 \\
\hline Carrot & 4 \\
\hline Cauliflower & 45 \\
\hline Corn & 20 \\
\hline Onion & 6 \\
\hline Potato & 26 \\
\hline Radish & 4 \\
\hline
\end{tabular}




\section{CONCLUSIONS}

The Innovative Seed sewing machine has a wonderful impact on agriculture. This seed plantation machine has great potential for increasing the productivity of the planting. Till now tractor was the main traction unit for nourishment in farming.

Hence there is a need to promote this technology and made available to even small-scale farmers with affordable prices. This machine can be made from raw materials also which saves the cost and can easily be manufactured. The only cost is of electronic components, motors, and sensors. Hence, by utilizing this machine, we can accomplish adaptability of separation and control profundity variety for various seeds, so it can be utilized to all seeds.

\section{ACKNOWLEDGEMENT}

Authors are grateful to Dr. A. Srinath and Dr. V Srikanth of KLEF for their valuable guidance and encouragement in carrying out this research work and their motivation in leading and fruition of project work.

\section{REFERENCES}

1. Prasanna Raut, Pradip Shirwale. (2016). A Survey on Smart Famer Friendly Robot Using Zigbee. International Journal of Emerging technology and Computer Science. Volume: 01

2. M. Priyadarshini, Mrs. L. Sheel. (2015). Command Based Self Guided Digging and Seed Sowing Rover. International Conference on Engineering Trends and Science \& Humanities. ISSN: 2348 - 8379, ICETSH

3. Du Danfeng, MaYan. (2010). Research on a Forestation Hole Digging Robot. Northeast Forestry University, Harbin. International Conference on Intelligent Computation Technology and Automation

4. Calvin Hung, Juan Nieto. (2013). Orchard Fruit Segmentation using Multi-spectral Feature Learning. IEE/RSJ International Conference on Intelligent Robot System Tokyo, Japan,3-7

5. Arora, Rahul, and S. S. Dhami. "Finite Element Analysis and Multibody Dynamics of 6-DOF Industrial Robot." World Academy of Science, Engineering and Technology, International Journal of Mechanical and Materials Engineering 4.11 (2017).

6. ThoratSwapnil V, Madhu. (2017) Design and Fabrication of Seed Sowing Machine”. International Research Journal of Engineering and Technology. Volume: 04

7. Kyada, A. R1, Patel, D. B.2. (2014) Design and Development of Manually Operated Seed Planter Machine. 5th International \& 26th All India Manufacturing Technology, Design and Research Conference (AIMTDR 2014), IIT Guwahati, Assam, India

A. Gbabo. (1998) Design and construction of a two-row cowpea and maize planter. Maintenance and Repair Unit, Agricultural Engineering Section, National Cereals Research Institute, Badeggi

8. Sowing and Planting Equipment. (2014). pp. 46-79. http://agricoop.nic.in/dac, division / machineryl / chap2a.pdf 